\title{
PLATO: Army applications
}

\author{
ZITA M. SIMUTIS and HELENA F. BARSAM \\ U.S. Army Research Institute for the Behavioral and Social Sciences \\ Alexandria, Virginia 22333
}

\begin{abstract}
The Army Research Institute for the Behavioral and Social Sciences conducts research in support of Army education and training. A review of training research using the PLATO computer system is presented. Research in the areas of curriculum development and evaluation, computer graphics, and game-based learning are discussed, including a description of the capabilities and limitations of the PLATO system as a research tool.
\end{abstract}

As part of its mission, the U.S. Army Research Institute (ARI) conducts basic and applied research in support of the Army's training requirements. This research is largely directed to the development of new technologies to improve the quality and cost-effectiveness of Army education and training. The problems faced in efficiently training new skills to several hundred thousand soldiers each year in short time periods are enormous. To further compound the training problem, the systems that soldiers must learn to operate and maintain are more complex today than in the past, and thus, today's soldier's job is technically more complex than ever before. In the past few years, ARI has conducted research investigating applications of computer-based instruction and other advanced technologies for training. These technologies offer the capability for efficient, individualized training. This paper will describe some of this research that used the PLATO computer-based education system. We will describe some completed research that investigated the feasibility of using computer-assisted instruction (CAI) for delivery of remedial basic skills instruction. We will also describe research that used PLATO as a research tool to look at effective use of gaming and graphics as training media.

\section{PLATO COMPUTER SYSTEM}

The PLATO system is a computer-based instructional system dedicated to the delivery of CAI and computermanaged instruction (CMI). PLATO terminals at the ARI are connected via dedicated telecommunications lines to a Control Data Corporation 6500 and CYBER 73 computers located at the University of Illinois, Urbana, which permit access to a large library of lessons with $7,000,000 \mathrm{~h}$ of instruction on hundreds of subjects. ${ }^{1}$ The PLATO terminal consists of a keyboard input device and a plasma panel or cathode-ray tube (CRT) display. The user communicates with the terminal either by the keyboard or a touch panel that allows the user to touch the screen to relay information. The system is capable

The opinions expressed in this paper are those of the authors and do not necessarily reflect official U.S. Army policy. of delivering CAI materials and is equipped with computer graphic capabilities. The system also has capabilities to manage instruction and automatically collects student data by storing student records, responses, and scores.

In addition to its CAI capabilities, the PLATO system offers many other options to the user. For example, PLATO has several communication options. PLATO system users are able to share information with each other through notes files designed as forums on a large variety of topics. Users can communicate with each other through personal notes that operate like an electronic mail system. Students can communicate with each other or with an instructor via student notes in which students and instructors record comments on progress and assignments. Instructors are also able to monitor students working on problems and interactively instruct or comment on the students' work in realtime. Users can also communicate on the system interactively to any other on-line user in real-time through a talk option.

The PLATO system also lends itself well to a research setting. The mechanics of PLATO, and its programming language, TUTOR, allow the researcher to incorporate CAI in to an experiment and easily manipulate the parameters of the research. For example, parameters of a CAI lesson can be manipulated to simply create several experimental conditions for the same basic lesson. PLATO provides the researcher with the means to present material in a standardized format, thereby reducing the risk of experimenter bias. PLATO, because it is a networked system, allows the researcher to collect data from multiple subjects at different locations while retaining control over the subjects' activities even when subjects are run in different conditions simultaneously. Subjects can be at one site, and the researcher can monitor and observe their activities from a different location. The PLATO system can be programmed for automatic data recording and data analysis. All subjects' responses (i.e., keypresses) can be stored and later analyzed. With PLATO's touch panel capabilities, subjects can respond by touching locations on the terminals' screen instead of typing in answers. This is 
particularly useful when using simulation techniques. Thus, PLATO can be used as an instructional system and a tool for experimental research.

\section{CURRICULUM DEVELOPMENT AND EVALUATION}

The ARI supports PLATO terminals at a research site at Fort Belvoir, Virginia. These terminals are used daily as an adjunct to basic skills training in the Army's Basic Skills Education Program (BSEP). This program is an extension of research ARI conducted in assessing the effectiveness of CAI for basic skills training (Simutis, Note 1). This study was conducted to determine the instructional effectiveness of CAI for high school equivalency or General Educational Development (GED) training. In addition, the study sought to identify implementation problems that occur when a new technology is introduced into a military classroom.

Eight PLATO terminals were introduced into the BSEP classroom at Fort Belvoir, Virginia, and instructors were trained in the use of the system. A CAI curriculum specifically tailored to the nceds of the Fort Belvoir Education Center was developed from existing lessons in language arts and mathematics available through the University of Illinois PLATO system. Instructional strategies among lessons varied considerably and included drill and practice, tutorials, tests, and game-based lessons. The CAI curriculum did not cover all topics covered in the traditional curriculum. For this reason. the CAI curriculum was supplemented with traditional instruction.

Subjects consisted of 32 soldiers enrolled in language art classes and 32 soldiers in mathematics classes. The soldiers within classes were randomly assigned to either traditional classroom instruction or traditional instruction with CAI instruction. Soldiers in the traditional instruction spent approximately $3 \mathrm{~h}$ daily receiving standard classroom instruction. Soldiers in the traditionalwith-CAI group spent $1 \mathrm{~h}$ using $\mathrm{CAI}$ and $2 \mathrm{~h}$ in traditional instruction.

Results of the study demonstrated that soldiers in the traditional-with-CAI instruction group scored higher on the High School Equivalency Examination after 6 weeks of training for both language arts and mathematics. The results and experience at Fort Belvoir clearly indicated that CAI can successfully be implemented with students at the lower abilities range. Partly as a result of this positive experience with CAI for remedial educational instruction, the Army is planning to considerably expand its use of CAI for use in BSEP.

The CAI curriculum continues to be used at Fort Belvoir daily and has been expanded to assist in teaching reading, providing supplementary information on high school and college-level subjects and for life-coping skills training.

\section{GRAPHIC CAPABILITIES}

The PLATO system has sophisticated graphic capabilities, ranging from line drawings to animation. ARI has exploited many of these graphic capabilities to determine how best to use graphic capabilities to enhance instruction. This section will discuss two completed experiments.

The first experiment was concerned with the instructional effectiveness of several levels of computer graphic complexity and the interaction effect of levels of graphics with identifiable learner aptitude characteristics. The experiment conducted by Moore, Nawrocki, and Simutis (Note 2) manipulated three different levels of computer graphics: high (animations plus line drawings), medium (line drawings only), and low (schematic representations and boxed alphanumerics). Three versions of a CAI lesson on the psychophysiology of audition were developed. Each version differed only in the level of graphics.

Subjects were 90 enlisted personnel who were randomly assigned to one of three graphic groups. Readily available aptitude measures, such as the General Tech. nical (GT) and Armed Forces Qualifying Test (AFQT) scores, were used to determine the extent of the relationship between aptitude and the type of graphics used. Four types of performance tests were administered to all subjects after they studied the lesson: (1) acquisition and use of principles, (2) identification of structure, (3) definitions and use of terminology, and (4) memory of specific facts.

The results of the experiment indicated that the level of computer graphics did not significantly affect success on the performance tests or time spent on the lesson. Subjects receiving simple graphics, such as boxed alphanumerics. combined with a textual CAI presentation performed at the same levels as subjects receiving more realistic visual displays and animations. Graphics level and GT category did not interact for a subsample of subjects $(n=51)$ for whom GT and AFQT scores were available. Although performance on the content test improved in the GT subsample as a function of aptitude as measured by the GT test, there were no indications of any Aptitude by Treatment interactions.

The failure to find differential effects for level of computer graphics was consistent with other researchers' findings. Simply adding more graphics did not necessarily increase instructional effectiveness. The next experiment addressed a different and, perhaps, a better question: How can graphics best be used to augment learning?

In the second experiment, we sought a task that required interaction with visual information in the real world that has significance in a military environment: terrain visualization. We manipulated the form of interaction that the student had with the computer graphics 
and considered soldiers' spatial ability as a factor (Simutis $\&$ Barsam, in press).

The PLATO system was used to present all training materials, collect some data, and perform statistical analyses. With ARI assistance, the University of Illinois Army Reserve Officers' Training Corps (ROTC) unit developed a series of computer-based lessons for training map reading. In addition to providing training in standard map reading topics, a method for generating terrain visualization displays from a contour map was used to provide practice with terrain visualization. The displays were generated by PLATO using bivariate normal probability density functions. The displays allowed students to practice with terrain visualization, contour interval-slope relationships, and landform identification. Simplified contour maps were displayed on the upper half of the terminal's screen. PLATO, upon user command, generated a graphic interpretation of the terrain on the lower half of the screen. The terrain interpretation could be graphed in either a twodimensional ground profile or as three-dimensional terrain visualization. Figures 1 and 2 provide examples of two-dimensional and three-dimensional terrain visualization, respectively.

Sixty enlisted personnel with limited map reading experience participated in the research. Soldiers' spatial ability was assessed through three spatial subtests from the Kit of Factor-Referenced Cognitive Tests (Ekstrom, French, Harman, \& Dermen, 1976) prior to the experiment. Subjects were assigned to one of three spatial ability groups (above average, average, and below average) based on their spatial ability score and then randomly

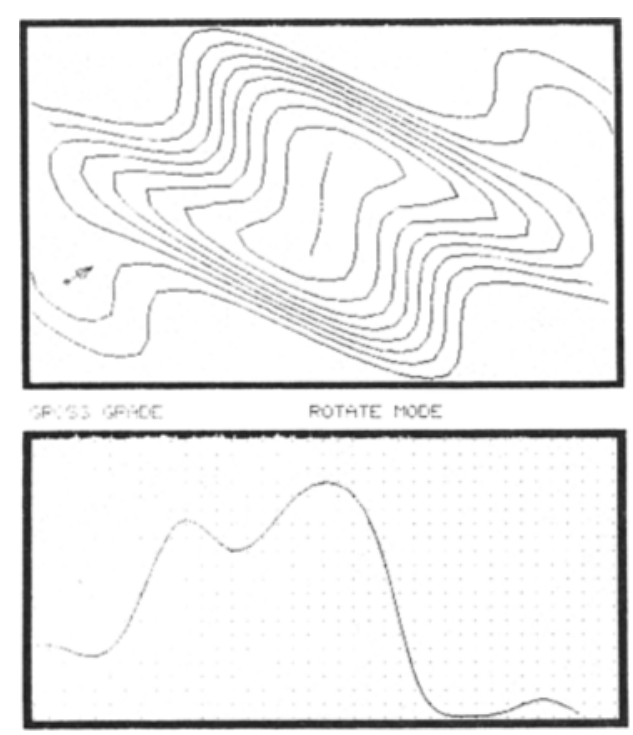

Figure 1. Example of a contour map and two-dimensional terrain visualization from the indicated point and direction on the contour map.

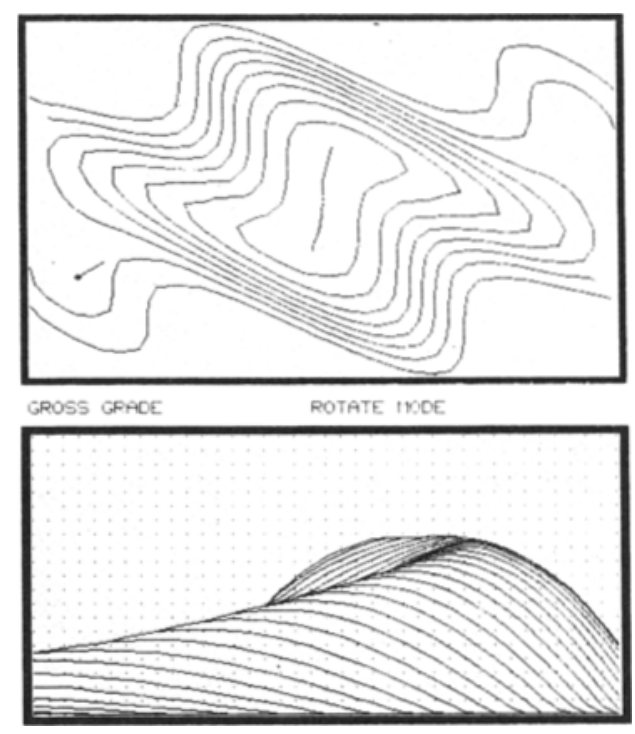

Figure 2. Example of contour map and three-dimensional terrain visualization from the indicated point and direction on the contour map.

assigned to one of the two training conditions using either interactive or noninteractive graphics.

All soldiers received about $1 \mathrm{~h}$ of CAI tutorial instruction on map reading techniques. Soldiers then practiced terrain visualization in either the interactive or noninteractive mode. The general approach was to have soldiers view a contour map and subsequently see the ground profile or land formation (generated by PLATO) associated with a specific place on the map. In the interactive version, a contour map was presented on which the soldier could move a cursor to choose a specific site and rotate the cursor from $0^{\circ}$ to $360^{\circ}$ to indicate the viewing direction. Upon pressing NEXT, PLATO displayed the terrain the individual would have seen if he or she had been standing on the site, looking in the chosen direction. The terrain was plotted in two or three dimensions.

The noninteractive graphic group practiced terrain visualization using the same contour maps, but the sites and directions for viewing were randomly selected by PLATO. Thus, the soldier had no control over the view he or she saw and acted only as a passive observer. Upon completing $1 \mathrm{~h}$ of terrain visualization practice, soldiers were tested on their ability to interpret contour maps via ARI's Relief Assessment Test (Potash, Farrell, \& Jeffery, 1978).

The results of the study yielded a significant interaction between spatial ability and training condition. A test of simple main effects indicated that for high spatial ability soldiers, interactive training was significantly more effective than noninteractive training. For these soldiers, interactive practice resulted in perfor- 
mance scores almost twice as high as noninteractive practice. Type of practice had no effect for average or below average spatial ability soldiers. In addition, high spatial ability soldiers had significantly higher performance scores than the average or below average soldiers, who did not significantly differ from each other.

One reasonable explanation for these results is as follows: The active choice process of the interactive practice training allowed the soldier to impose structure in the learning situation in the absence of any preexisting structure, but only if the soldier had sufficient spatial abilities to select information-rich views. Because the average and below average spatial ability soldier lacked the same level of spatial skills, he or she could not make good choices of views to see, so that his or her choices were essentially random.

Results of the study have several implications and serve as an example of the need to consider the characteristics of trainees and the training methods to be used when investigating a new training technology. The study also suggests that an instructional technique to improve the efficiency of computer graphic terrain visualization practice for all spatial ability-level soldiers would be to enhance the level of structure inherent to the practice itself. For example, the computer could initially guide soldiers in selecting views, showing them how small changes in cursor position or direction change the terrain display. Using more sophisticated techniques, the computer could individualize the amount and type of structure for soldiers of different spatial ability levels.

The two experiments described above are illustrations of how the ARI has used PLATO as a research tool to investigate issues in designing computer-based instruction. In both experiments, PLATO was utilized to deliver instruction, deliver experimental and control conditions, record all responses, collect data, and analyze data. By using PLATO, we were assured standardization in instruction and conditions and were able to investigate issues of computer graphics in instruction. During our experiment on interactive and noninteractive computer graphics, we encountered one disadvantage to using the PLATO system. The routines to generate the terrain visualizations were mathematically complex and required considerable computer time. Because PLATO is a timeshared system dedicated to instruction, we found it was efficient only to collect data in the early morning or late evening, when the student use of the system was low. During other times of the day, the terrain visualizations took a painstaking amount of time to be displayed, which subsequently affected subject motivation. However, manufacturers recently have designed terminals that can be used as stand-alone PLATO terminals. These terminals can be hooked into the PLATO system or can be used as a stand-alone microcomputer operated from disks. It might have been more advantageous to utilize a stand-alone PLATO terminal for the map reading research because it would have minimized the time to generate and plot the displays.

\section{GAME-BASED LEARNING}

In this section, we will discuss options on PLATO available to the researcher that allow precise experimenter control. We will illustrate the discussion with examples from research on game-based learning.

ARI has used PLATO in research designed to determine the effectiveness of gaming as a training technique. The broad objective of these experiments was to determine whether exposure to a game requiring the use of logic would result in positive transfer to understanding logic circuit diagrams and fault diagnosis. Further information about the development of lessons can be found in Yeager and Simutis (Note 3). We will describe one experiment briefly to illustrate the capabilities of PLATO as a research tool, interspersing PLATO capabilities with the experimental design to highlight how we used PLATO to manipulate variables and store data.

\section{Phase 1}

The subjects in the experiment were 60 enlisted personnel. They were seated at PLATO terminals and asked to complete an on-line biographical questionnaire. The biographical information (Figure 3), collected from the soldiers included personal information such as age, rank, and time in service. Soldiers were also asked whether they were familiar with computers, electronics, or auto mechanics. Finally, soldiers were asked whether they were familiar with any of 16 games. Upon completing the information survey, they were shown a summary page listing all of their answers, which they could then change if necessary. The data were stored in a

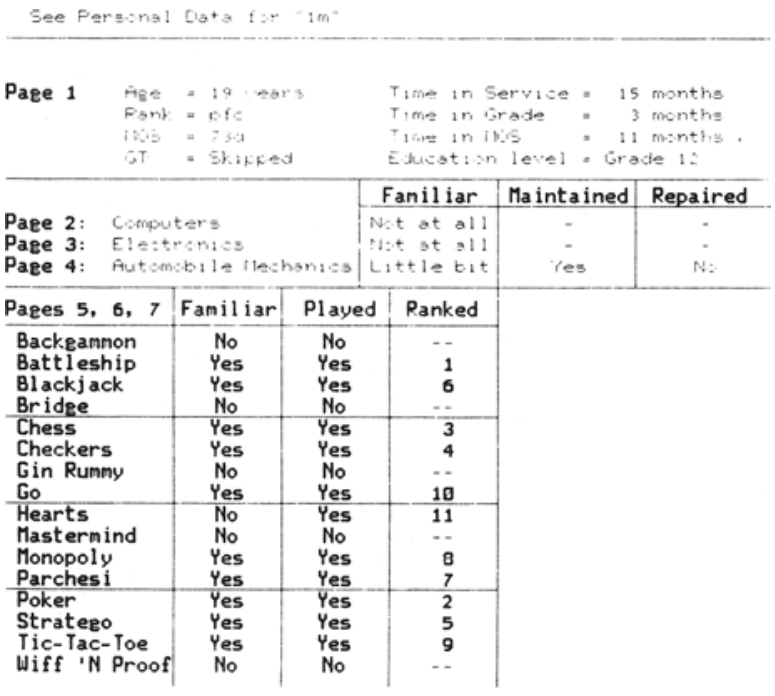

Figure 3. Biographical questionnaire used to collect personal data on-line. 
format that allowed the experimenter to reconstruct the summary page for each soldier. The data may also be processed automatically, so that specific items can be correlated with other data.

\section{Phase 2}

Next, the soldiers were routed to a tutorial program on the interpretation of logic circuit symbols and diagrams. In this tutorial, they were taught the meaning of the logic circuit symbols and practiced determining outputs given the inputs. After completing the instruction, they were given a test with 12 simplified diagrams with mixed symbols in which they matched the output values for each diagram. Incorrect answers received explanatory feedback.

\section{Phase 3}

The soldiers then practiced solving logic circuit diagrams. Figure 4 shows an example of this practice. They were given diagrams on the terminal and were required to mark specified output values. For each diagram, the soldiers were shown the input values and asked to specify one or more output values. At the bottom of the screen, there were boxes with " 0 " and " 1 " in them; the subjects either touched the appropriate box, or they typed the number, and then they touched the output they wished to mark. When the subjects completed marking the diagram, they touched the DONE box to have it judged. Incorrectly marked outputs were crossed out, and subjects were told how many they had wrong.

Using an exercise editor written in TUTOR code, the experimenter can set any of the following criteria for practice session described above (see Figure 5): (1) Amount of time allowed-This parameter allows the

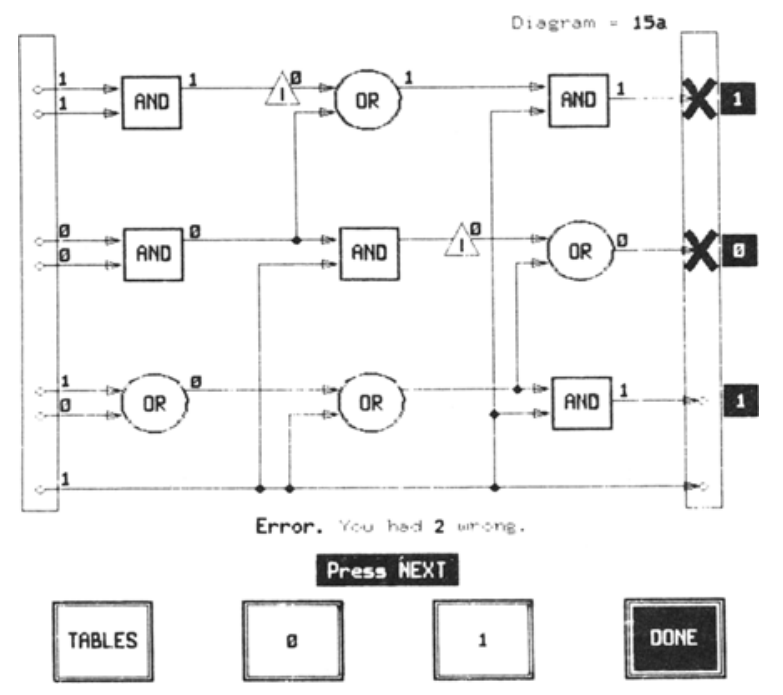

Figure 4. Example of logic circuit diagram practice with remedial feedback.

\begin{tabular}{|c|c|c|}
\hline CRITERION & VALUE & LESSON STATUS \\
\hline Time (in minutes) & A Not set & $\mathbf{J}$ \\
\hline $\begin{array}{l}\text { Maximum time } \\
\text { (in minutes) }\end{array}$ & B 68 & K completed \\
\hline Number of problems & C 28 & L completed \\
\hline Total right & D Not set & n \\
\hline $\begin{array}{l}X \text { consecut ive right } \\
\text { after Y problems }\end{array}$ & E Not set & N \\
\hline $\begin{array}{l}X \text { percent right } \\
\text { after } Y \text { problems }\end{array}$ & F Not set & 0 \\
\hline Total wrone & G Not set & $\mathbf{P}$ \\
\hline $\begin{array}{l}X \text { consecutive wrons } \\
\text { after } Y \text { problems }\end{array}$ & H Not set & Q \\
\hline $\begin{array}{l}X \text { percent wrong } \\
\text { after } Y \text { problems }\end{array}$ & I Not set & $\mathbf{R}$ \\
\hline
\end{tabular}

Press NEXT or BACK to store

Figure 5. Exercise editor for setting parameters for logic circuit practice.

experimenter to terminate a subject's work when the set time expires. The subject may finish working on the current diagram, but he may not start a new diagram. (2) Maximum amount of time allowed-When the time period set by the experimenter expires, the subjects are stopped from whatever they are currently doing, and the lesson is terminated. (3) Number of diagrams requiredThis parameter can be set to end the lesson when the subject completes the specified number of diagrams. (4) Success criteria-This parameter can be set to end the lesson when any of the following types of criteria are met: total correct, consecutive correct after a specified number of problems, and percent correct after a specified number of problems. (5) Failure criteria-This parameter ends the lesson if any of the types of criteria outlined above are met, except that wrong answers are counted. Figure 6 shows an example of the parameters the experimenter can set for the logic circuit testing. In this example, the practice was completed after the maximum amount of time of $60 \mathrm{~min}$ or when $20 \mathrm{prob}$ lems had been completed.

If the criteria are attached to a subset of diagrams, then matching a criterion can allow branching to another subset of diagrams. Thus, the experimenter can establish levels of difficulty and specify the algorithms for moving to a different subset of diagrams. The experimenter can specify the diagrams in any order, or the diagrams can be given in random order for each subject. For each diagram, the input values may be specified directly, be allowed to remain at their default setting, or be reassigned randomly for each subject. If the input values are changed, all values for all gates and outputs are recomputed, and the changes affect only that particular instance of the particular diagram. Therefore, it is possible to use the same diagram more than once but with different input values. 
See Practice Session Data for " $1 \mathrm{~m}$ "

\begin{tabular}{|c|c|c|c|c|}
\hline Num & Diagram & Right & Poss & Time \\
\hline 1. & Int & 1 & 1 & 248,5 \\
\hline 2. & $1 a$ & 1 & 1 & 27.2 \\
\hline 3. & $15 a$ & 3 & 3 & 74.1 \\
\hline 4. & 110 & 1 & 3 & 194.1 \\
\hline 5. & $13 a$ & 3 & 3 & 227.2 \\
\hline 6. & $3 b l$ & 2 & 3 & 209.7 \\
\hline 7. & $4 b$ & 3 & 3 & 163.5 \\
\hline 8. & $7 b$ & 3 & 3 & 217.3 \\
\hline 9. & $1 \mid b 1$ & 3 & 3 & 133.9 \\
\hline 10. & $3 b$ & 2 & 3 & 140.0 \\
\hline
\end{tabular}

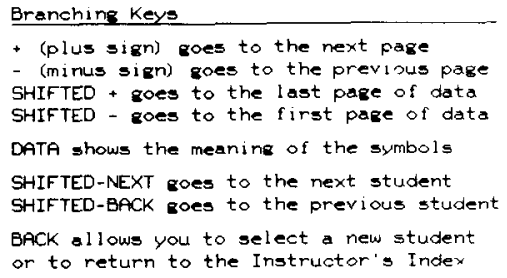

Figure 6. Summary of data stored for logic circuit practice.

After the soldiers completed the logic circuit practice, the program automatically stored the score. The following data were stored for each diagram: name of the diagram, time spent on the diagram, the correct values of the outputs, and the required values of each output as assigned by the soldiers. Data were stored by sign-on records and can be retrieved for individual or group analysis. Figure 6 shows data stored for 10 problems.

\section{Phase 4}

Next, the soldiers either played blackjack or mastermind or continued with instruction on PLATO, depending upon their group assignment. For the game groups, all individual responses were stored, as well as overall performance scores on the game.

\section{Phase 5}

Soldiers then received a tutorial lesson designed to teach fault-isolation procedures. The lesson showed a mock-up of a computer circuit board and explained how the lights on the circuit board operate, how to relate the lights on the circuit board to symbols on a diagram, and how to determine if there is a malfunction by comparing expected outputs from the diagram with lights on the circuit board. Soldiers were then given a short quiz of 12 items to determine if they could identify malfunctions. All diagrams used in the quiz were drawn on the screen. Incorrect answers received corrective feedback. Soldiers then practiced faultisolation procedures for $60 \mathrm{~min}$. This practice was identical to the quiz following the fault-isolation instruction.

\section{Phase 6}

Finally, the soldiers were tested on their performance on fault-isolation problems. The problems were similar to those used in the practice described above. The soldiers were shown a circuit board with lights either on or off. Then, using the indicator lights, the soldiers determined if the circuit was operating correctly. The soldiers indicated a malfunction by touching the indicator light. If there was no malfunction, the soldiers touched a NO MALFUNCTION box at the lower left corner of the screen. Figure 7 shows an example of fault-isolation diagnosis. When the soldiers were sure they were correct, they touched a DONE box. They were told whether or not they were correct. The soldiers had to successfully solve a problem before they could continue to the next one.

Parameters for fault isolation are similar to those described previously for the logic circuit practice. However, for this lesson, it is not necessary to indicate "required output." Instead, the experimenter may specify the type of malfunction for each diagram (see Figure 8). The options are as follows: (1) Default setting-The experimenter may choose the default setting in which each diagram is preset with a specified malfunction gate. In the default setting, approximately $20 \%$ of all diagrams are specified as having no malfunction. (2) No malfunction-The experimenter may set the diagram as having no malfunction. (3) Malfunction at a specified gate number-The experimenter may select the gate for the malfunction to occur. (4) A definite malfunction, but at a random gate-The experimenter may choose to have PLATO generate a random malfunction for the diagram. (5) A malfunction according to the probabilities preset for the list of diagramsThe experimenter may specify, for example, that four of every five diagrams presented should have a malfunction. An example of the parameters for fault diagnosis is located in Figure 8.

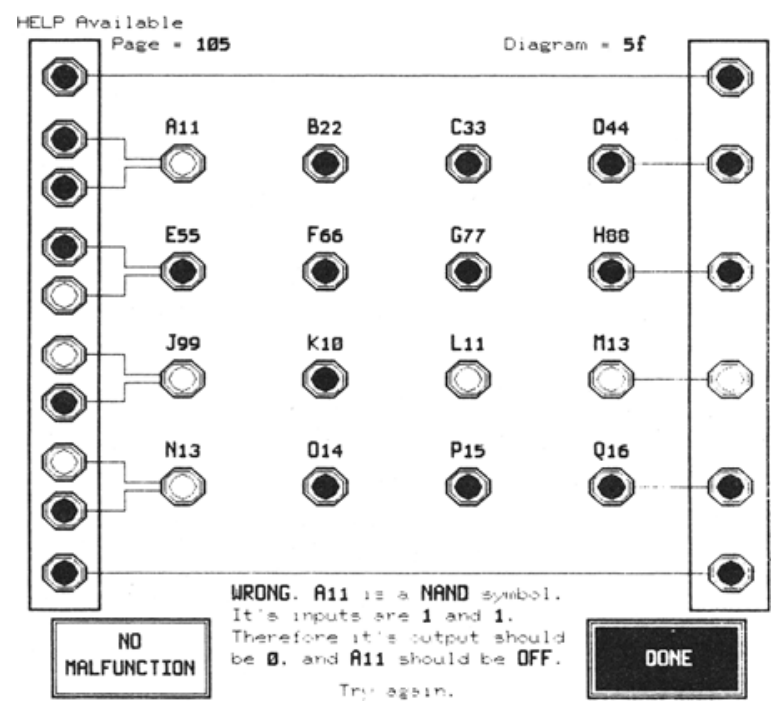

Figure 7. Example of fault-isolation diagnosis with remedial feedback. 


\begin{tabular}{|c|c|c|}
\hline CRITERION & VALUE & LESSON STATUS \\
\hline Tame $41 \mathrm{n}$ mirutesi & A Not set & $\mathrm{J}$ \\
\hline $\begin{array}{c}\text { Maximum time } \\
\text { Iin mirutes } \\
\end{array}$ & B 60 & $k \quad$ ecmplet $=1$ \\
\hline Number of problems & C 2. & L completed \\
\hline Total right & D 15 & 11 ampleted \\
\hline $\begin{array}{c}X \text { consecut twe right } \\
\text { after Y problems }\end{array}$ & E Not set & $N$ \\
\hline $\begin{array}{l}X \text { percent } r \text { rght } \\
\text { ofter Y problem= }\end{array}$ & F not set & 0 \\
\hline Total wrong & a 10 & $\mathbf{P}$ ampleted \\
\hline $\begin{array}{c}X \text { consecutive wrong } \\
\text { after } Y \text { problems }\end{array}$ & H Not set & 0 \\
\hline $\begin{array}{l}X \text { percent wrong } \\
\text { after } Y \text { problems }\end{array}$ & I Not set & $R$ \\
\hline
\end{tabular}

Figure 8. Exercise editor for setting parameters for faultisolation diagnosis.

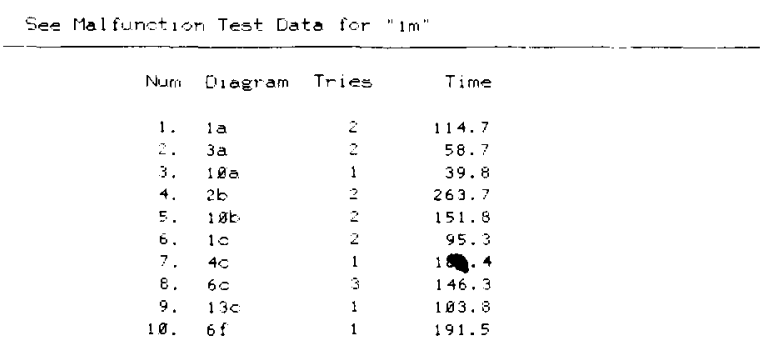

Figure 9. Summary of data stored for fault-isolation diagnosis.

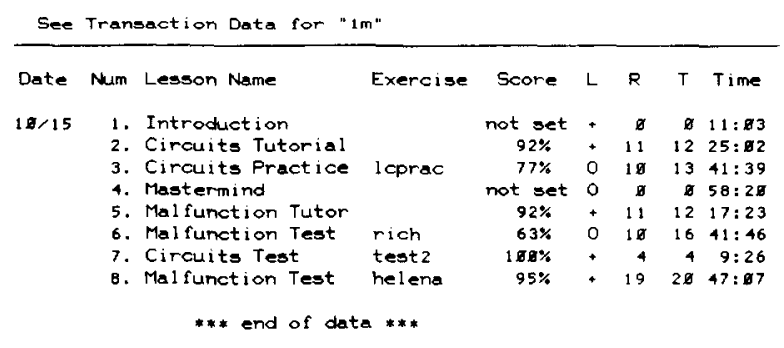

Figure 10. Data summary page for soldiers' activities.

Data collected are similar to those described previously for the logic circuit practice test. Figure 9 shows data stored for the fault-isolation diagnosis.

Data are also stored in a summary fashion in order to facilitate the researcher synthesis of the data. The data are stored by subject, and the data summary includes all the lessons completed and scores obtained. The data summary page is shown in Figure 10.

In some sense, detailed prescriptions that are allowed in the lessons created specifically for our work in gaming/ maintenance are overkill. That is, there are many instructional options, and every response a student makes while at the terminal is stored by the computer. But we were looking for flexibility in the design of the lessons to allow other research uses and for instructional applications. Both of these objectives were achieved.

\section{CONCLUSION}

We have briefly described some of the ways ARI has used the PLATO system as a vehicle for conducting research in CAI, effects of graphics on learning, and computer gaming. As a research tool, PLATO has met a variety of standard research needs, such as stimulus display, variable manipulation, data collection, and data analysis. System features have allowed us to collect data remotely, have required programming done remotely with interaction via talk and note options, have run subjects in different conditions simultaneously, and have provided an audit trail on experiment development, among other things. At the same time, all research products developed for use in the research are currently in use in military and civilian education and training. For example, the basic skills curricula are extensively used at Fort Belvoir. The lesson on the psychophysiology of audition is available on several PLATO systems and is used by students at more than 100 colleges and universities. The map reading lessons are used by ROTC students at many universities. The logic circuit lessons have been adapted for use with high school students. Not only have we easily accomplished some of our research objectives by using PLATO in our research, we have provided tangible products that military personnel and civilians can use to enhance training and education.

\section{REFERENCE NOTES}

1. Simutis, Z. M. CAI as an adjunct to teach basic skills. Paper presented at the meeting of the American Educational Research Association, San Francisco, April 1979.

2. Moore, M. V., Nawrocki, L. H., \& Simutis, Z. M. The instructional effectiveness of three levels of graphics displays for computer-assisted instruction (Tech. Paper 359). Alexandria, Va: U.S. Army Research Institute for the Behavioral and Social Sciences, April 1979.

3. Yeager, R. F., \& Simutis, Z. M. Computer-based electronics maintenance training: Description of lessons (Research Product 79-10). Alexandria, Va: U.S. Army Research Institute for the Behavioral and Social Sciences, September 1979.

\section{REFERENCES}

Ekstrom, R. B., French, J. W., Harman, H. H., \& Dermen, D. Manual for kit of factor-referenced cognitive tests. Princeton, N.J: Educational Testing Service, 1976.

Potash, L. M., Farrell, J. P., \& Jeffery, T. A technique for assessing map relief legibility. Cartographic Journal, 1978, 15, 28-35.

Simutis, Z. M., \& Barsam, H. F. Terrain visualization and map reading. In H. L. Pick \& L. Acredelo (Eds.), Spatial orientation. New York: Plenum, in press.

\section{NOTE}

1. Commercial designations are used for precision of reporting. Their use does not constitute endorsement by the Army Research Institute or the U.S. Army. 